\title{
A NOTE ON TEXTS
}

All references to Shakespeare's plays are to The Norton Shakespeare, eds Stephen Greenblatt et al. (New York: W.W. Norton, 1997). 
